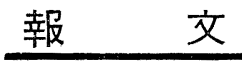

\title{
Interfacial Electrical Study on Deposition of Poly (vinyl acetate) Latex on Fibers*
}

\author{
Hisashi TAmaI, Tsuruo KonO, and Toshiro Suzawa \\ Department of Applied Chemistry, Faculty of Engineering, \\ Hiroshima University (Higashihiroshima-shi, Hiroshima)
}

\begin{abstract}
The amounts of poly(vinyl acetate) latex deposited on Nylon-6, polyacrylonitrile and cotton fibers were measured as functions of time and $\mathrm{pH}$ and compared with those of polystrene and poly (ethyl acrylate) latices. The results were considered in terms of the interaction due to electrostatic force and van der Waals force.

The amounts of these latices deposited on Nylon-6 fiber decreased highly with increasing $\mathrm{pH}$ and it was found that the electrostatic interaction was a main factor for the deposition.

The amounts of polystyrene and poly(ethyl acrylate) latices deposited on polyacrylonitrile fiber and cotton fiber were high in spite of large repulsive interaction due to electrostatic force and slightly decreased for increase in $\mathrm{pH}$, that is, an increase in electrostatic repulsive interaction. However, the amounts of poly(vinyl acetate) latex deposited on polyacrylonitrile fiber and cotton fiber were very low in spite of the almost same repulsive interaction as those of polystyrene and poly (ethyl acrylate) latices.

Based on these results, it is proposed that a steric repulsion due to water-soluble polymer layer, e.g., poly (vinyl alcohol) layer which may be present on poly(vinyl acetate) latex surface, acts between the latex and polyacrylonitrile fiber or cotton fiber.
\end{abstract}

\section{Introduction}

The particle deposition onto fibers and the desorption of adhered particles are important in detergency, especially in removal of partic= ulate soil. For the study on particle deposition or desorption, the use of polymer latices seems to be excellent because polymer latices consist of monodispersed spherical particles. From these points of view, the deposition of various pol= ymer latices onto fiber has been studied ${ }^{1) \sim 7}$.

In a recent study ${ }^{8}$, we have dealt with the deposition of styrene-acrylamide copolymer latex onto polyamide (Nylon-6), polyester [poly (ethy= lene terephthalate) $(\mathrm{PET})$ and polyacrylonitrile (PAN) fibers. In the case of this latex, the deposition rates onto Nylon-6 fiber and PET fiber increased and those onto PAN fiber decreased with increasing acrylamide fraction

*This paper is Part IX in a series "Interfacial elec= trical studies on the deposition of polymer latexes onto fabrics and the removal of these deposited latexes." Part VII : H. Tamai, A. Iida, T. Suzawa, Colloid Polymer Sci., in press. in latex particles. On the other hand, the viscometric measurements of this latex disper= sions indicated that water-soluble polymer layer was present on the particle surface. On the basis of these results, the authors have intro= duced that a certain repulsive force, e.g. a steric repulsive force due to water-soluble polymer layers, acts between the latex particle and PAN fiber, in addition to the electrostatic force and van der Waals force.

Okamura et al. have reported that on the particle surface of poly (vinyl acetate) latex pre= pared in the presence of emulsifier, the hydro $=$ lysis takes place readily at room temperature and neutral $\mathrm{pH}$, and poly (vinyl alcohol) is formed $^{9)}$. This fact makes us to imagine the presence of water-soluble polymer layer, that is, poly (vinyl alcohol) layer on the particle surface. Thus, it is thought that the inter= action between colloidal particles having watersoluble polymer layer and fibers can be further clarified by investigating the deposition of poly (vinyl acetate) latex onto fibers.

In this report, the deposition of poly(vinyl 
acetate) latex on PAN, Nylon-6 and cotton fibers is investigated and the amounts of latex deposited are compared with those of poly (ethyl acrylate) and polystyrene latices. The results obtained are considered in terms of the inter= action due to electrostatic force and van der Waals force. In particular, regarding the des position of poly(vinyl acetate) latex on PAN and cotton fibers, the operation of a steric re= pulsion due to poly (vinyl alcohol) layer on the particle surface is proposed, in analogy with styrene-acrylamide copolymer latex ${ }^{8}$.

\section{Experimental}

\subsection{Materials}

Vinyl acetate (Katayama Chemical Ind.) and ethyl acrylate (Wako Pure Chemical Co., Ltd.) were distilled three times under reduced pres= sure. Potassium persulfate (Wako Pure Chem = ical Co., Ltd.) was recrystallized twice from water. Sodium chloride, sodium hydroxide, and hydrochloric acid (Wako Pure Chemical Co., Ltd.) were all analytical grade materials and were used without further purification. Dis= tilled and deionized water was used throughout the experiments.

Poly (vinyl acetate) (PVAc) and poly (ethyl acrylate) (PEA) latices were prepared in the absence of emulsifier, using potassium persulfate as initiator ${ }^{(0), 11)}$. The polymerization conditions are shown in Table-1.

The particle sizes of PVAc latex and PEA latex were determined by electron microscopy and a soap titration method, respectively. Since these preparations were carried out at high meters of the latices were relatively large. The monomer concentration, the mean particle dias

preparation of polystyrene (PS) latex was de= scribed in the previous paper ${ }^{1)}$. The latices obtained were dialysed using well-boiled Visking dialysis tubing for about 1 week, and then elecs trodialysed for about 1 week.

The fabrics of PAN fiber (Mitsubishi Rayon Co., Ltd.; Muslin), Nylon-6 fiber (Toray Co., Ltd.; Taffeta) and cotton fiber (Kanebo Co., Ltd.) were used. These fabrics were purified by the methods described previously ${ }^{1,2}$.

\subsection{Methods}

Amounts of latex deposited. Similarly to the technique described previously ${ }^{1,2)}, 2 \mathrm{~g}$. weighed fabric (about $0.1 \times 0.2 \mathrm{dm}$ swatches) was immersed in $5 \times 10^{-2} \mathrm{dm}^{3}$ latex dispersion $\left(1 \mathrm{~g} \cdot \mathrm{dm}^{-3}\right.$ solid content) for a prescribed time, and the amount of latex deposited was deter= mined from the change in solid content of latex dispersion. The solid content was obtained by dry weight.

Electrokinetic measurements. The $\zeta$-po $=$ tentials of latex particles and the fibers were measured by the methods of microelectrophore= sis and streaming potential, respectively, as described previously ${ }^{1,2)}$.

Deposition experiments and electrokinetic measurements were carried out as a function of $\mathrm{pH}$ at $25^{\circ} \mathrm{C}$ and $10^{-3}$ ionic strength. The $\mathrm{pH}$ was varied with hydrochloric acid sodium hydroxide. The ionic strength was adjusted with sodium chloride.

\section{Result and Discussion}

Fig.-1 shows the amounts of PVAc latex A and PS latex deposited on Nylon-6 fiber as a function of time at $\mathrm{pH}$ 3.1.

These amounts deposited increased with in $=$ Table-1 Preparation of latices.

\begin{tabular}{l|c|c|c|c}
\hline \multirow{2}{*}{ Latex } & \multicolumn{2}{c|}{ PVAc } & \multirow{2}{*}{ PEA } & PS \\
\cline { 2 - 4 } & $\mathrm{A}$ & $\mathrm{B}$ & & \\
\hline Vinyl acetate (M) & 2.88 & 1.56 & - & - \\
Ethyl acrylate (M) & - & - & 1.85 & - \\
Styrene (M) & - & - & - & 0.501 \\
KPS* (M) & $1.5 \times 10^{-2}$ & $1.0 \times 10^{-2}$ & $0.4 \times 10^{-3}$ & $2.48 \times 10^{-3}$ \\
Polymerization temp. ( $\left.{ }^{\circ} \mathrm{C}\right)$ & 70 & 70 & 70 & 70 \\
Polymerization time $(\mathrm{h})$ & 1.5 & 1.5 & 5 & 28.5 \\
Particle diameter $(\mu \mathrm{m})$ & 0.59 & 0.48 & 0.38 & 0.46 \\
\hline
\end{tabular}

*Potassium persulfate creasing deposition time, and $13.3 \mathrm{mg}$ of PVAc latex and $7.5 \mathrm{mg}$ of PS latex deposited on $1 \mathrm{~g}$ of fiber at $24 \mathrm{~h}$. Fig. -2 shows the amounts of PVAc A, PS, and PEA latices deposited on PAN fiber as a function of time at $\mathrm{pH} 3.1$.

The deposition of PVAc latex on PAN fiber was markedly dif= 


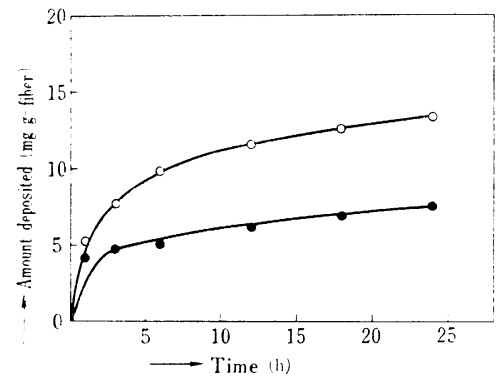

: PVAc (A)

: PS

Fig.-1 Amounts of latices deposited on Nylon-6 fiber as a function of time at $\mathrm{pH} 3.1,10^{-3}$ ionic strength and $25^{\circ} \mathrm{C}$.

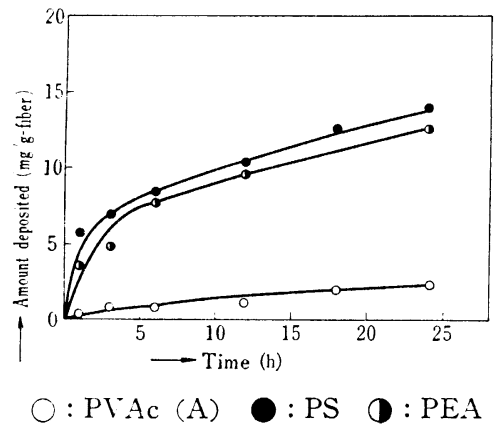

Fig.-2 Amounts of latices deposited on PAN fiber as a function of time at $\mathrm{pH} 3.1,10^{-3}$ ionic strength and $25^{\circ} \mathrm{C}$.

ferent from those of other latices. The amounts of PVAc latex deposited were low and scarcely increased with the increase in deposition time. On the other hand, the amounts of PS latex deposited on PAN fiber increased with increasing time and they were higher than those on Nylon -6 fiber. Fig. -3 shows the amounts of the three kinds of latices deposited on cotton fiber at $\mathrm{pH}$ 3.1. Though PVAc latex scarcely deposited on cotton fiber, PEA latex deposited readily.

If it is assumed that depositing particles are accomodated in a hexagonal close-packed array on the fiber surface, the amount of PVAc latex deposited on Nylon-6 fiber at $24 \mathrm{~h}$ corresponds to about 17 percentage of fractional coverage. In this calculation, the surface area of fiber was obtained from the diameter of monofilament ( 3 denier). Thus, the amounts of these latices deposited tend to increase even at $24 \mathrm{~h}$ of de= position time. This suggests that the amounts

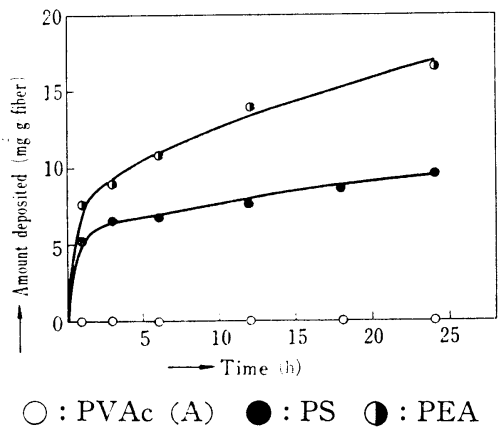

Fig.-3 Amounts of latices deposited on cotton fiber as a function of time at $\mathrm{pH} 3.1,10^{-3}$ ionic strength and $25^{\circ} \mathrm{C}$.

of the latices deposited depend on the deposition rate and the deposition is irreversible under the conditions used.

Regarding the change in $\mathrm{pH}$, Table-2 shows the relation between the amounts of the latices deposited at $24 \mathrm{~h}$ and $\mathrm{pH}$.

Table-2 The amounts of latices deposited at $24 \mathrm{~h}$ of deposition time, $25^{\circ} \mathrm{C}$, and $10^{-3}$ ionic strength.

\begin{tabular}{l|r|r|r|r}
\hline \multirow{2}{*}{ Fiber } & pH & \multicolumn{2}{|c}{$\begin{array}{c}\text { Amount of deposited latex } \\
\text { (mg/g-fiber) }\end{array}$} \\
& & PVAc(B) & PS & PEA \\
\hline \multirow{3}{*}{ Nylon-6 } & 3.1 & 13.8 & 7.5 & - \\
& 4.8 & 1.0 & 0 & - \\
& 10.5 & 0.5 & 0 & - \\
\hline \multirow{3}{*}{ PAN } & 3.1 & 1.0 & 14.0 & 15.8 \\
& 5.3 & 1.0 & 12.6 & 10.9 \\
\hline \multirow{3}{*}{ Cotton } & 10.5 & 1.0 & 7.0 & - \\
& 3.1 & 2.9 & 9.6 & 16.5 \\
& 5.1 & 0.6 & 7.6 & 9.1 \\
& 10.5 & 0.5 & 5.8 & - \\
\hline
\end{tabular}

In order to compare PVAc latex with PS and PEA latices, the results of PVAc latex B are shown, since the particle size is almost the same as that of PS latex. As shown in $\mathbf{T a}=$ ble-2, the amounts of PVAc and PS latices deposited on Nylon-6 fiber decrease remarkably with increasing $\mathrm{pH}$, and the latices scarcely deposit at alkaline $\mathrm{pH}$. Though the amounts of PS and PEA latices deposited on PAN fiber are high and decrease with increasing $\mathrm{pH}$, those of PVAc latex are almost constant for 
the change in $\mathrm{pH}$ and low. The deposition on cotton fiber exhibited the same behavior as that on PAN fiber.

As described in the previous papers ${ }^{1) \sim 4), 6), 7)}$, the deposition phenomena of latex particles on fibers can be considered by the coagulation theory of colloidal particles. That is, the de= position is mainly influenced by the interaction between a latex particle and the surface of fiber. In this study, therefore, the observed phenom $=$ ena of the three kinds of latices were consid= ered from these points of view.

In general, the interaction energy between a latex particle and the fiber can be estimated by the incorporation of electrostatic interaction en = ergy and van der Waals interaction energy. The electrostatic (double layer) interaction en = ergy $\left(V_{E}\right)$ is calculated by the equation $(1)^{12)}$, as the energy between a sphere and the flat plate.

$$
\begin{aligned}
V_{E} & =\frac{a \varepsilon}{4 k T}\left[\left(\dot{\varphi}_{1}^{2}+\dot{\varphi}_{2}^{2}\right) \ln \frac{\exp (2 \kappa H)-1}{\exp (2 \kappa H)}\right. \\
& \left.+2 \dot{\psi}_{1} \dot{\psi}_{2} \ln \frac{\exp (\kappa H)+1}{\exp (\kappa H)-1}\right] \quad \text { (1) }
\end{aligned}
$$

where $a$ is the radius of a latex particle, $\varepsilon$ is the dielectric constant of medium, $k$ is the Boltsmann constant, $T$ is the absolute tempe $=$ rature, $H$ is the distance between a latex par= ticle and the fiber, $\kappa$ is the Debye-Hückel pa $=$ rameter, and $\phi_{1}$ and $\dot{\varphi}_{2}$ are surface potentials of a latex particle and the fiber, respectively.

The interaction energy of van der Waals forces $\left(V_{A}\right)$ is calculated by the equation $(2)^{13)}$.

$$
\begin{aligned}
V_{A} & =-\frac{A}{6 k T}\left[\frac{2 a(H+a)}{H(H+2 a)}\right. \\
& \left.-\ln \frac{H+2 a}{H}\right]
\end{aligned}
$$

where $A$ is the Hamaker constant. As $A, 5 \times$ $10^{-21} \mathrm{~J}$ was used on the basis of the value for polystyrene in water ${ }^{14)}$.

Using $\zeta$-potentials as surface potentials in $\mathrm{Eq}(1)$, the electrostatic interaction energies were calculated. The $\zeta$-potentials of the latices measured are shown in Fig. -4 , as a function of $\mathrm{pH}$. The $\zeta$-potentials of the latices were negative at all $\mathrm{pH}$. These negative values inc= reased with increasing $\mathrm{pH}$ and exhibited the constant ones at alkaline $\mathrm{pH}$. The constant values increased in the order : $\mathrm{PVAc}<\mathrm{PS}<\mathrm{PEA}$.

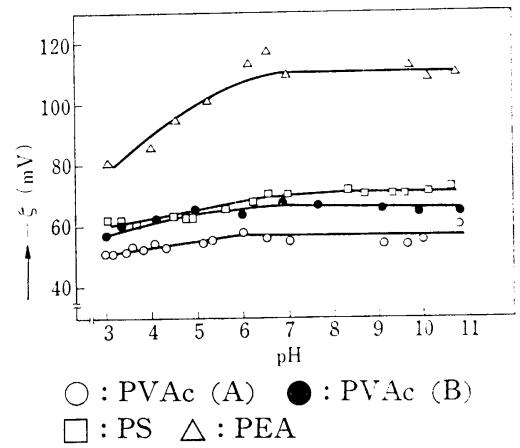

Fig.-4 $\zeta$-Potentials of latices as a func= tion of $\mathrm{pH}$ at $10^{-3}$ ionic strength and $25^{\circ} \mathrm{C}$.

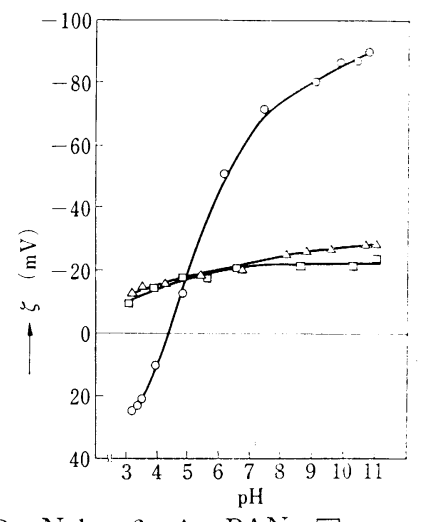

0 : Nylon-6 $\triangle$ : PAN $\square:$ cotton

Fig. -5 -Potentials of fibers as a funce tion of $\mathrm{pH}$ at $10^{-3}$ ionic strength and $25^{\circ} \mathrm{C}$.

The $\zeta$-potentials of the fibers are shown in Fig. $-\mathbf{5}$, as a function of $\mathrm{pH}$. The $\zeta$-potential of Nylon-6 fiber was positive at acidic $\mathrm{pH}$ and exhibited the isoelectric point at $\mathrm{pH}$ 4.3. The negative $\zeta$-potential at alkaline $\mathrm{pH}$ increased with increasing $\mathrm{pH}$. The negative $\zeta$-poten= tials on PAN fiber and cotton fiber increased with increasing $\mathrm{pH}$ in the region of acidic $\mathrm{pH}$ to neutral $\mathrm{pH}$, and those were constant at alkaline $\mathrm{pH}$.

Based on these $\zeta$-potentials, the electrostatic interaction energies were calculated as a func= tion of separation distance between a latex particle and the fiber. The total interaction energies $\left(V_{T}\right)$ due to $V_{A}$ and $V_{E}$ calculated at $\mathrm{pH} 3.1$ are shown in Fig. -6 .

$r_{T}$ between Nylon-6 fiber and the latices are attractive energies because the $\zeta$-potentials are opposite in sign. In the case of PAN fiber 


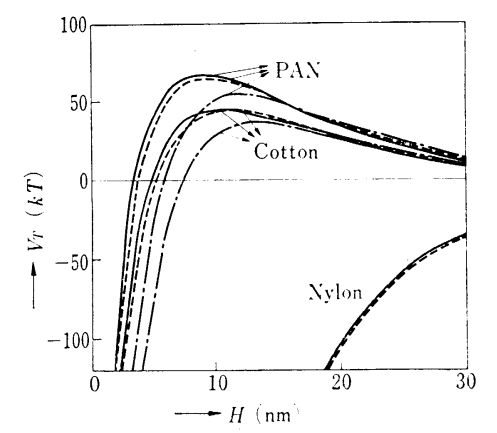

- : PVAc (B) …... : PS -.- : PEA

Fig.-6 Total interaction energy between latex particles and fibers as a function of separation distance at $\mathrm{pH} 3.1,10^{-3}$ ionic strength and $25^{\circ} \mathrm{C}$.

and cotton fiber, $V_{T}$ have maximum values $\left(V_{T \max }\right)$ at a certain separation distance. There= fore, the deposition of the latices on the fibers seems to be mainly influenced by the magnitude of $V_{T \max }$. $V_{T \max }$ between the latices and the fibers are shown in Table-3, as a function of $\mathrm{pH}$.

Table-3 $V_{T \max }$ between latex particles and fibers at $25^{\circ} \mathrm{C}$ and $10^{-3}$ ionic strength.

\begin{tabular}{l|r|r|r|r}
\hline Fiber & pH & $\begin{array}{c}\text { PVAc } \\
(\mathrm{B})\end{array}$ & $\begin{array}{r}V_{T \max }(\mathrm{kT}) \\
\text { PS }\end{array}$ & PEA \\
\hline \multirow{3}{*}{ Nylon-6 } & 3.1 & $<0$ & $<0$ & - \\
& 4.8 & 189 & 181 & - \\
& 10.5 & 1759 & 1876 & - \\
\hline \multirow{3}{*}{ PAN } & 3.1 & 67 & 65 & 54 \\
& 5.3 & 121 & 163 & 97 \\
& 10.5 & 189 & 189 & 153 \\
\hline \multirow{3}{*}{ Cotton } & 3.1 & 46 & 45 & 38 \\
& 5.1 & 171 & 116 & 137 \\
& 10.5 & 227 & 220 & 186 \\
\hline
\end{tabular}

$V_{T \max }$ of PVAc and PS latices for Nylon-6 fiber increased highly with increasing $\mathrm{pH}$. In the case of PAN fiber and cotton fiber, $V_{T \max }$ of the three kinds of latices increased gradually with increasing $\mathrm{pH}$ and those values were ap= proximately same at each $\mathrm{pH}$. From these results, it is supposed that the depositing a= mounts of the latices decrease with increasing $\mathrm{pH}$ regardless of the kind of fiber or latex, and those of PVAc B, PS, and PEA latices on PAN fiber or cotton fiber are almost same at same $\mathrm{pH}$.
The relation between the amounts deposited in Table-2 and $V_{T \max }$ in Table-3 was con= sidered. In the case of Nylon-6 fiber, the amounts of PVAc and PS latices deposited decrease highly with increasing $V_{T \text { max }}$, though the amount of PVAc latex is larger than that of PS latex at no repulsive energy. In partic= ular, these latices scarcely deposit on Nylon-6 fiber in the presence of high $V_{T \max }$. This suggests that the electrostatic interaction is an important factor for the deposition of latex on Nylon-6 fiber. On the other hand, the amounts of PVAc latex deposited on PAN fiber and cotton fiber are almost constant and low in

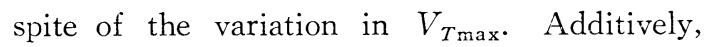
from the comparison of Table-2 and Table-3, it seems that the amounts of PS and PEA latices deposited on PAN fiber and cotton fiber depend slightly on $V_{T \max }$, though the amounts deposited decrease with increasing $V_{T \text { max }}$. That is, the amounts of PS and PEA latices depos= ited on PAN fiber and cotton fiber are larger than those on Nylon-6 fiber, in spite of high $V_{T_{\max }}$.

The above-mentioned results regarding PAN fiber and cotton fiber suggest the operation of other interaction forces in addition to the elec= trostatic force and van der Waals force. In regard to PVAc latex prepared in the presence of emulsifier, Okamura et $a l .{ }^{9)}$ have reported that the hydrolysis takes place readily on the particle surface at room temerature and neutral $\mathrm{pH}$, and poly (vinyl alcohol) is formed. Though PVAc latex used in this study was prepared in the absence of emulsifier, the formation of poly (vinyl alcohol) seems to be caused by potassium persulfate used as initiator. That is, poly (vinyl alcohol) layer may be present on the particle surface of PVAc latex, and this poly(vinyl alcohol) layer seems to influence on the deposi= tion of PVAc latex on PAN fiber and cotton fiber. Recently, the authors ${ }^{8)}$ have found that on the deposition of styrene-acrylamide copoly= mer latex on PAN fiber, a certain repulsive force acts between the latex particle and PAN fiber, besides the electrostatic force. As this repulsive force, a steric repulsive force due to water-soluble polymer layer, which is present on the particle surface, has been introduced. Thus, in analogy with styrene-acrylamide cos 
polymer latex, a steric repulsive force due to poly (vinyl alcohol) layer may act between PVAc latex particle and PAN fiber or cotton fiber, as schematically represented in Fig. $-7(\mathrm{~A})$.

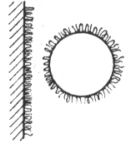

(A)

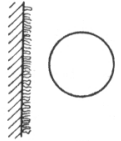

(B)
(A) : PVAc (B) : PS and PEA

Fig. -7 Schematic representation of interaction between PAN or cotton fiber and latex paro ticles.

It is thought that because of this repulsive force, the amounts of PVAc latex deposited on PAN fiber and cotton fiber are almost constant and low in spite of the variation in $V_{T \max }$. On the other hand, a certain attractive force seems to act between PS or PEA latex particle and PAN fiber or cotton fiber, besides the electro= static force and van der Waals force. For exs ample, a force due to bridging may act, as represented in Fig.-7(B). It may be attributed to this force that the amounts of PS and PEA latices deposited on PAN fiber and cotton fiber are larger than those on Nylon-6 fiber, in spite of high $V_{T \max }$.

Furthermore, in order to consider the influs ence of poly (vinyl alcohol) layer of PVAc latex particle, the PVAc latex $\mathrm{B}$ particles deposited on Nylon-6 fiber were observed by scanning electron microscopy. A typical photograph is given in Fig.-8, together with that of PS latex. PS latex particles deposit on Nylon-6 fiber connected to each other, e.g., like a rosary, as described in the previous paper ${ }^{6)}$. However, in the case of PVAc latex, it was observed that

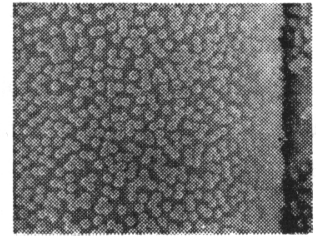

(A) : PVAc

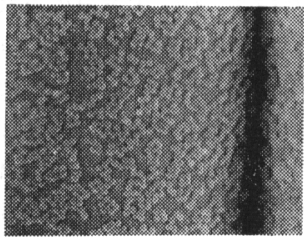

(B) : PS
Fig.-8 Scanning electron micrographs of latex particles deposited on $\mathrm{Ny}=$ lon-6 fiber at $\mathrm{pH} 3.1,24 \mathrm{~h}$ of deposition time and $10^{-3}$ ionic strength. many particles tended to deposit as individual particles. Because of the steric repulsive force due to poly (vinyl alcohol) layer, PVAc latex particles may deposit as individual particles. This supports the influence of poly(vinyl alcos hol) layer mentioned above for the deposition of PVAc latex.

(Received Sept. 24, 1983)

\section{References}

1) T. Suzawa, H. Tamai, H. Shirahama, and K. Yamamoto, Nippon Kagaku Kaishi, 1979, 16.

2) H. Tamai, T. Hakozaki, and T. Suzawa, Colloid Polymer Sci., 258, 870 (1980).

3) H. Tamai and T. Suzawa, Colloid Polymer Sci., 259, 1100 (1981).

4) H. Tamai and T. Suzawa, J. Colloid Inter= face Sci., 88, 372 (1982).

5) H. Tamai, A. Hamada, and T. Suzawa, J. Colloid Interface Sci., 88, 378 (1982).

6) H. Tamai, Y. Nagai, and T. Suzawa, J. Colo loid Interface Sci., 91, 464 (1983).

7) H. Tamai, I. Kimura, and T. Suzawa, Colloid Polymer Sci., in press, "The Electrokinetic Study on the Deposition of Polystyrene Latex onto Nylon Fiber".

8) H. Tamai, A. Iida, and T. Suzawa, Colloid Polymer Sci., in press, "The Surface Char= acterization of Styrene-Acrylamide Copolymer Latex Particles and their Deposition onto Fi= bers".

9) S. Okamura and T. Motoyama, Kogyo Kagaku Zasshi, 58, 113 (1955).

10) T. Matsumoto, M. Okubo, and T. Imai, Kos bunshi Ronbunshu, 32, 229 (1975).

11) S. Hayashi and N. Hojo, Makromol. Chem., 177, 1215 (1976).

12) R. Hogg, T.W. Healy, and D.W. Fuerstenau, Trans. Faraday Soc., 62, 1638 (1966).

13) A. Kitahara, Kagaku no Ryoiki, 24, 402 (1970).

14) R.H. Ottewill and J. N. Shaw, Discuss. Fara $=$ day Soc., 42, 154 (1966).

\section{ポリ䣷酸ビニルラテックスの繊維への 付着性に関する界面電気的研究 玉井久司・河野鶴雄・須沢利郎 広島大学工学部応用化学 (東広島市)}

ポリ酢酸ビニルラテックスのナイロンー6, ポリアクリ ロニトリル及び木綿繊維への付着量を時間及び $\mathrm{pH}$ に関 して測定し，ポリスチレン及びポリアクリル酸エチルラ テックスの結果と比較した。結果を静電力及びファンデ ルワールスカによる相互作用の点から考察した。

ナイロン 6-纎維への付着量は, $\mathrm{pH}$ の増加と共に急激 に減少し, 静電的な相互作用が付着に対する主たる因子 